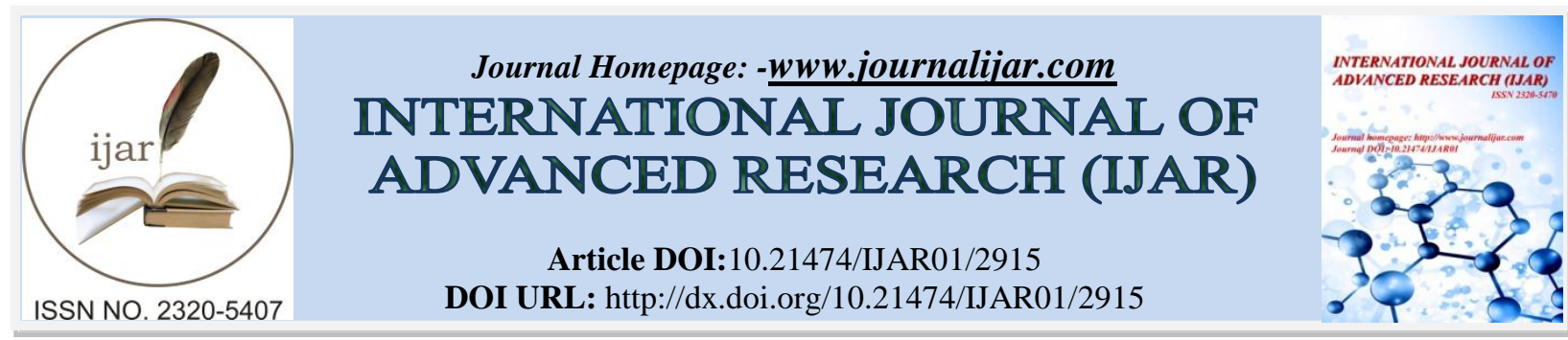

RESEARCH ARTICLE

\title{
ARGINASE ENZYME ACTIVITY AND LACTOFERRIN PROTEIN CONCENTRATION IN EGYPTIAN DIABETIC PATIENTS.
}

\section{Mohamed A. El-Desouky ${ }^{1}$, Sanaa Osman ${ }^{2}$, Nashwa M. Shams Eldin ${ }^{1}$ and Ibrahim Emaraa ${ }^{3}$.}

1. Faculty of Science, Cairo University, Department of Chemistry, Lab of Biochemistry.

2. Faculty of Science, Cairo University, Department of Chemistry.

3. NationalDiabetes and Endocrinology Institute.

\section{Manuscript Info}

\section{Manuscript History}

Received: 24 November 2016

Final Accepted: 25 December 2016

Published: January 2017

Key words: -

(1) type 2 diabetes (2) Arginase (3)

Lactoferrin,LF

\section{Abstract}

Purpose: This work has been carried out to evaluate the arginase activity andlactoferrin (LF) level as biochemical markers in type 2 diabetic Egyptian.

Subjects and Methods: The present study consisted of 84 patients classified into threegroups: Uncontrolled diabetic patients [G1], Control diabetic patients [G2], Normal healthy subjects [G3]. Lactoferrin concentration was measured using ELISA technique. Arginase andother biochemical parameters were measured by using Jenway $6105 \mathrm{uv} / \mathrm{vis}$ spectrophotometer. Finally, all the results were statistically analyzed andcompared with normal subjects [G3].

Results: The mean sera value of both arginase and LF was found to beelevated in uncontrolled type 2 diabeticpatient group[G1] and controlled type 2 diabetic patientgroup[G2] compared to normal healthygroup [G3].

Conclusion: Both arginase and LF are considered as good biomarkers fordiagnosis of type 2 diabetes and for detection of the best and most effectivemethod for the treatment.

Copy Right, IJAR, 2016, All rights reserved.

\section{Introduction:-}

Diabetes is defined as a chronic metabolic disorder characterized by a dysfunction in insulin secretion and/or insulin action, also known as hyperglycemia, and is divided into type 1 diabetes mellitus, type 2 diabetes mellitus (T2DM), and gestational diabetes mellitus (GDM) [1]. Diabetes is defined by the WHO that a plasma glucose $>200 \mathrm{mg} / \mathrm{dl}$, a fasting plasma glucose of $>126 \mathrm{mg} / \mathrm{dl}[2]$.

Arginase is the fifth and final step in the urea cycle. It converts L- arginine into ornithine and urea (9). Although the function of the arginase enzyme in the liver is the catalysis of arginine hydrolysis to ornithine and urea, in extrahepatic tissues the function of the enzyme is essentially unknown. Normal blood serum contains only trace of arginase. However, in some pathological conditions, especially in various types of cancer, the elevated activity levels of arginase enzymes in the serum have been reported in many studies [3].

Lactoferrin is an iron-binding diferric glycoprotein present in most of the exocrine secretions. The major role of lactoferrin, which is found abundantly in colostrum, is antimicrobial action for the defense of mammary gland and 
the neonates. Lactoferrin consists of two equal halves, designated as N-lobe and C-lobe, each of which contains one iron-binding site. While the N-lobe of lactoferrin is known for its enhanced antimicrobial effect, the C-lobe of lactoferrin mediates various therapeutic functions which are still being discovered. The potential of the $\mathrm{C}$-lobe in the treatment of diabetes has been indicated [4].

\section{Objective:-}

The aim of this project is to clarify the relation between LF and arginase by indicating the effect of LF in diabetic patients which is counter and handling to the effect of arginase. Also, to evaluate the arginase activity and lactoferrin protein concentration levels in diabetic patients and to detect whether these parameters can be used to improve the clinical assessment of diabetes mellitus and considered as biomarkers for monitoring, the progression and recurrence of diabetes mellitus. In addition, the work aims to assess the role of these parameters in monitoring diabetes mellitus therapy and detect the best and most effective method for the treatment.

\section{Material and Methods:- \\ Patients:-}

The present study consisted of subjects of 84 patients. They were classified into three groups: Untreated Type 2 Diabetes group [G1]: consisting of 32 type 2 diabetic patients, the duration of disease ranged from (15 months 96 months). Treated type 2 diabetes group [G2]: consisting of 32 type 2 diabetic patients treated with tablets (Gliclazide), and duration of disease ranged from (24-120) years. Normal healthy subjects group [G3]: consisting of 20 normal healthy persons. All groups included in this study were matched in age, BMI and gender. They free from heart diseases, muscle disorders and liver diseases.

\section{Biochemical Measurements:-}

All biochemical parameters including serum creatinine, liver enzymes as (ALT) and(AST) and random blood glucose were determined by using Jenway $6105 \mathrm{uv} /$ visspectrophotometer. The method used for the determination of arginase activity was based on thecolorimetric determination of urea by condensation with diacetylmonoxime in anacid medium in the presence of ferric chloride (oxidant) and carbazide (accelerator)using Jenway 6105 uv/vis spectrophotometer.

Lactoferrin, LF, level was measured using ELISA technique. This assay employed a quantitative sandwich enzyme immunoassay technique, whichmeasured LF in 5 hours. A monoclonal antibody specific for human LF hadbeen precoated onto a microplate. Human LF in standards and samples wassandwiched by the immobilized antibody and biotinylated polyclonal antibodyspecific for human LF, which was recognized by a streptavidinperoxidaseconjugate. All unbound material was then washed and a peroxidase enzyme substratewas added. The color development was stopped and the intensity of the color wasmeasured.

\section{Statistical Analysis:-}

The data were evaluated with One Way ANOVA used to declare the significant difference between groups at $\mathrm{p}<0.05$. Duncan multiple comparisons test at $\mathrm{p}<0.05$ was used to declare the significant difference between each two groups. Both tests used to compare both serum arginase activity andserum lactoferrinconcentration in different studied groups where significantvalues represented by $(\mathrm{P}<0.05)$ while non-significant values represented by $(\mathrm{P}$ $>0.05)$.

\section{Results:-}

The range of serum arginase activity in uncontrolled diabetic type 2 patients group (G1) was (86.30-141.80 U/L), with a mean \pm SD $[114.49 \pm 14.82] \mathrm{U} / \mathrm{L}$. The range of serum arginase activity in controlled diabetic type 2 patients group (G2) was $(43.50-70.70 \mathrm{U} / \mathrm{L})$, with a mean $\pm \mathrm{SD}[56.07 \pm 8.71] \mathrm{U} / \mathrm{L}$. The range of serum arginase activity in normal healthy subjects (control group) (G3) was (10.90-33.50 U/L), with a mean \pm SD [21.77 \pm 6.51$] \mathrm{U} / \mathrm{L}$.The range of serum LF concentration in uncontrolled diabetic type 2 patients group (G1) was (40.20-67.50 ng/ml), with a mean \pm SD $[52.35 \pm 6.75] \mathrm{ng} / \mathrm{ml}$. The range of serum LF concentration in controlled diabetic type 2 patients group (G2) was $(29.90-48.50 \mathrm{ng} / \mathrm{ml})$, with a mean $\pm \mathrm{SD}[39.73 \pm 4.05] \mathrm{ng} / \mathrm{ml}$. The range of serum LF concentration in normal healthy subjects (control group) (G3) was $(9.70-19.10 \mathrm{ng} / \mathrm{ml}$ ), with a mean $\pm \mathrm{SD}[14.01 \pm 3.00] \mathrm{ng} / \mathrm{ml}$. Statistical analysis using ANOVA test revealed thatsignificant elevation in the mean levels of both serum arginase activity and lactoferrin concentration in uncontrolled diabetic type 2 patients group (G1) compared to controlled diabetic type 2 patients group (G2) and normal healthy subjects(G3).Significant elevation in mean values of serum 
arginase activity was found in controlled diabetic type 2 patients group (G2) compared to normal healthy subjects (control group) (G3) as shown in table (1).

In uncontrolled type 2 diabetic patient group (Group 1), there is correlation between arginase and urea at $P(<0.01)$ and $\mathrm{r}=(0.909)$. The correlation of LF and total cholesterol, triglycerides, HDL and LDL -cholesterol in both diabetic groups are shown in table(2) and table(3).

\section{Discussion:-}

The present study may consider a link between the effect of serum arginase activity and serum lactoferrin concentration in one study for diabetes mellitus disease.We showed in this study that there is inverse relation between the effect of both arginase activity and lactoferrin concentration on Egyptian diabetic patients, where elevation of serum arginase activity in type 2 diabetes causing vascular dysfunction may as a result of decreasing insulin level and elevation of ROS at the same time serum lactoferrin concentration start to raise as immune response to counteract the inflammation that result from elevation of arginase and ROS.

This may be explained by hyperglycemia or insulin resistance in that appears to be involved in the widespread induction of arginase observed in diabetes as exposure of vascular cells to high concentrations of glucose triggers a rise in arginase activity.Consequently, Egyptian diabetic patients will have a weakened immune resulting from the hyperglycemia and decreasing insulin signaling which has anti-inflammatory effect, as a result the Egyptian diabetic patients will be exposed to inflammation and cell damage that cause increasing of oxidative stress as increasing ROS that cause vascular dysfunction and inducing the immune system yielding some signals, and some pathways that stimulate increasing serum arginase activity.Also, elevation of serum arginase level in control diabetic patient Egyptian begin to decrease somewhat due to controlling glucose levels by handling with tablets or exogenous insulin by syringe which modulate the immune system through adjusting the insulin level by its action as antiinflammatory and restoring the elasticity of vascular cells.

Table 1:- Biochemical Data in Patient and Control Groups

\begin{tabular}{|c|c|c|c|}
\hline $\begin{array}{l}\text { Groups } \\
\text { Biochemical } \\
\text { Data }\end{array}$ & $\begin{array}{c}\text { Uncontrolled } \\
\text { Diabetic Type } 2 \\
\text { Patients } \\
\text { (G1) }\end{array}$ & $\begin{array}{c}\text { Control } \\
\text { Diabetic Type } 2 \\
\text { Patients } \\
(\mathrm{G} 2) \\
\end{array}$ & $\begin{array}{l}\text { Normal } \\
\text { Subjects } \\
\text { (G3) }\end{array}$ \\
\hline Serum Arginase Activity (U/L) & $114.49 \pm 14.82^{c}$ & $56.07 \pm 8.71^{b}$ & $21.77 \pm 6.51^{a}$ \\
\hline $\begin{array}{c}\text { Serum Lactoferrin } \\
\text { Concentrations }(\mathrm{ng} / \mathrm{ml})\end{array}$ & $52.35 \pm 6.75^{\mathrm{c}}$ & $39.73 \pm 4.05^{b}$ & $14.01 \pm 3.00^{\mathrm{a}}$ \\
\hline $\begin{array}{l}\text { Serum Urea Concentration } \\
(\mathrm{mg} / \mathrm{dl})\end{array}$ & $54.51 \pm 6.68^{b}$ & $53.57 \pm 5.29^{b}$ & $17.70 \pm 4.35^{\mathrm{a}}$ \\
\hline $\begin{array}{c}\text { Serum T.Cholesterol } \\
\text { Concentration } \\
(\mathrm{mg} / \mathrm{dl})\end{array}$ & $239.52 \pm 9.32^{c}$ & $215.85 \pm 4.31^{b}$ & $114.67 \pm 2.95^{\mathrm{a}}$ \\
\hline $\begin{array}{l}\text { Serum Triglycerides } \\
\text { Concentration } \\
(\mathrm{mg} / \mathrm{dl})\end{array}$ & $183.15 \pm 2.69^{c}$ & $172.30 \pm 1.92^{b}$ & $75.23 \pm 0.87^{\mathrm{a}}$ \\
\hline $\begin{array}{c}\text { Serum HDL Cholesterol } \\
\text { Concentration } \\
(\mathrm{mg} / \mathrm{dl})\end{array}$ & $28.29 \pm 1.50^{\mathrm{a}}$ & $32.24 \pm 1.41^{b}$ & $42.77 \pm 2.39^{c}$ \\
\hline $\begin{array}{c}\text { Serum LDL Cholesterol } \\
\text { Concentration } \\
(\mathrm{mg} / \mathrm{dl})\end{array}$ & $175.16 \pm 10.83^{c}$ & $149.16 \pm 5.10^{b}$ & $56.84 \pm 5.15^{\mathrm{a}}$ \\
\hline
\end{tabular}

Data are presented by Mean \pm SD for Arginase activity, Lactoferrin, Urea, Cholesterol, Triglycerides, HDL and LDL Cholesterol concentrations.

*= There is a significant difference by using One Way ANOVA at $p<0.05$.

The same letter means that there is no significant difference between the two groups by using Duncan multiple comparison test at $\mathbf{p}<0.05$.

The different letters mean that there is a significant difference between the two groups by using Duncan multiple comparison test at $\mathbf{p}<0.05$ 
Table 2:-Correlation of lactoferrin concentration with lipid profile in group (G1).

\begin{tabular}{|c|c|c|}
\hline Lipid profile & $\mathrm{r}$ & $P$-value \\
\hline $\begin{array}{c}\text { Serum T. Cholesterol Concentration } \\
(\mathrm{mg} / \mathrm{dl})\end{array}$ & $\mathbf{0 . 5 9 6}$ & \\
\hline $\begin{array}{c}\text { Serum Triglycerides Concentration } \\
(\mathrm{mg} / \mathrm{dl})\end{array}$ & $\mathbf{0 . 9 7 8}$ \\
\hline $\begin{array}{c}\text { Serum HDL Cholesterol } \\
\text { Concentration } \\
(\mathrm{mg} / \mathrm{dl})\end{array}$ & $\mathbf{- 0 . 9 3 2}$ & \\
\hline $\begin{array}{c}\text { Serum LDL Cholesterol } \\
\text { Concentration(mg/dl) }\end{array}$ & $\mathbf{0 . 6 3 0}$ & \\
\hline
\end{tabular}

Table 3:-Correlation of lactoferrin concentration with lipid profile in group (G2).

\begin{tabular}{|c|c|c|}
\hline Lipid profile & r & \\
\hline $\begin{array}{c}\text { Serum T. Cholesterol Concentration } \\
(\mathrm{mg} / \mathrm{dl})\end{array}$ & $\mathbf{0 . 7 0 4}$ & \\
\hline $\begin{array}{c}\text { Serum Triglycerides Concentration } \\
(\mathrm{mg} / \mathrm{dl})\end{array}$ & $\mathbf{0 . 8 8 8}$ & \\
\hline $\begin{array}{c}\text { Serum HDL Cholesterol } \\
\text { Concentration } \\
\text { (mg/dl) }\end{array}$ & $\mathbf{- 0 . 9 6 2}$ \\
\hline $\begin{array}{c}\text { Serum LDL Cholesterol } \\
\text { Concentration(mg/dl) }\end{array}$ & $\mathbf{0 . 9 7 8}$ & \\
\hline
\end{tabular}

While most studies have focused on the coronary circulation and large conduit blood vessels, the role of arginase in mediating diabetic endothelial dysfunction in other vascular beds has not been fully investigated [5].

In this study, there is a correlation between arginase and urea at $\mathrm{P}(<0.01)$. Diabetes was accompanied by increased food consumption, amino acid metabolism, and ratio of blood glucagon to insulin, all of which would tend to increase urea cycle and arginase [6].Arginase,whichis presentintwoisoformscatalyzesthefinalstepoftheureacycleyielding 1-ornithineandureafrom L-arginine[7].It was demonstrated thatelevated levels of arginase and lower serum arginine levels are associated with increased urea production by RBCs from DM patients might have a negative impact on the functionality of vascular endothelial cells to impair NO synthesis by endothelial cells [8].The deamination of amino acids reaction was catalyzed by many enzymes and excreted in the form of urea in diabetes. The increase in activity of liver arginase in diabetes may be a response to this high rate of protein catabolism [9].

Lactoferrin is stored in secondary granules of neutrophils and is released in response to activation of proinflammatory cytokines such as TNF- $\alpha$, IL-6, and IL-8. The serum level of lactoferrin, which is very low in the physiological state, increases significantly with infection. By studying the results of serum LF concentration in Egyptian diabetic patients with type 2, it was shown that diabetic patients (uncontrolled and control patients) may be accompanied with complications like inflammation as a result of elevation of arginase level and ROS which lead to secretions of LF from neutrophils with higher levels as immune response and that may be explained by deficiency in secretion of insulin from pancreas or low efficiency of insulin effect on the target cells comparing to healthy subjects. As LF has anti-inflammatory effect and its secretion is one of the immune response processes, it was noted that, elevation of LF levels could decrease serum arginase activity by increasing the production of NO at the same time decreasing levels of ROS which cause vascular dysfunction in response to cytokines.

LF elevation may be due to inflammation accompanied to diabetes complication that result from elevation of serum arginase activity and ROS levels. Also, elevation of lipid profile may explain this elevation in lactoferrinconcentration. Our results observed that there is correlation between lactoferrin,cholesterol, triglycerides (TG), HDL cholesterol and LDL cholesterol at $(P<0.01)$ in non-control diabetic group (Group 1), control diabetic group (Group 2) and normal healthy subject (Group 3).Also,our study about the diabetic Egyptian patients showed that there was significant difference between each two groups of this experiment represented by $P(<0.05)$. 
The anti-inflammatoryeffect of lactoferrin takes place by suppressionof TNF- $\alpha$ and IL-1 $\beta$, which were activated in TNB-Inducedcolitis. Theinhibitory effect of lactoferrinonproinflammatory cytokines suggested that lactoferrinreleased from secondary granules of activated neutrophilsat an inflammatory site may provide an inhibitoryfeedback mechanism to prevent excessive neutrophilaggregation and activation[10].

Improving insulin action [by the administrationof insulin or an insulin-sensitizer as rosiglitazone]could increase lactoferrin production and improve the neutrophil function.Insulin under strict euglycemia was ableto prime neutrophil function in adult healthy humans andmodulates neutrophil activity not only by gaining a bettermetabolic control but also through a direct effect of thehormone. Thus, improved insulin action might act as an immunoregulatory agent to turnimmune cells to a primed state, which prepared the cell fora greater immune responseand increased cytokine secretion. Increased insulin actionor sensitivity would allow a more balanced neutrophilresponse, increasing the efficiency of the immune system[11].

The concentration of circulating lactoferrin was significantly decreased in individuals with an altered glucose toleranceand might contribute to dyslipidemia In addition, the circulating lactoferrin concentration was linked to the plasma lipid profile where it was demonstratedthe effect of lactoferrin as antiatherosclerosis byreducing the plasma and hepatic concentrations of cholesteroland triglycerides in mice and increased plasma concentrationsof HDL cholesterol[12]. However, it wasobserved thatconcentration of lactoferrin was lower in diabetic patients as compared to control group[13]. On the other hand, it wasexplored that no difference in lactoferrin was found among the patients with non-insulin-dependent diabetes mellitus (NIDDM) group and healthy controls group[14].

Experimental studies in cells demonstrated that lactoferrinsignificantly inhibited/decreased intracellular reactive oxygenspecies (ROS) levels in a dose-dependent manner and protected fromoxidative stress. As FFA produce an increase in oxidative stress, the putative decrease of FFA induced bylactoferrincould also contribute. In fact, different protective functions against inflammation have been attributed to lactoferrin, and the preservation of adipose tissue integrity and the associationswith lactoferrin with CRP and antioxidant enzymes may beinterpreted in this scenario. It was found that lactoferrin led to decreased TG concentration in adiposetissue explants[15].

Our experimental results for elevation of lactoferrin concentration in uncontrolled diabetic patient group (group 1) are in agreement with [16]using ELISAand[17]who found a significant increase in the concentration of lactoferrin in NIDDM in comparison to control group. It was found that significant increases in the concentration of lactoferrin in the diabetic subjects $(30 \%)$ in comparison with $(17 \%)$ of healthy subjects suggesting that disease-specific mechanisms might be responsible andthese increased concentrations may reflect neutrophil priming caused by hyperglycemia.

Lactoferrin also directly interacted with modified LDL to prevent its interaction with scavenger receptors. A region rich in basic amino acid residues near the lactoferrin $\mathrm{N}$ terminus is responsible for the interaction with acetylated or oxidized LDL. This cationic part of lactoferrin strongly binds modified LDLs via electrostatic interaction with positively charged Arg residues at physiological PHs [12].

The mechanism of LF action might involve several processes, such as inhibition of adipogenesis, decrease of dietary triglyceride absorption, elevation of HDL cholesterol possessing anti-atherogenic properties, inhibition of accumulation of oxidized LDL cholesterol forms in macrophages and protection against formation of foam cells. LF also increased the susceptibility of cells to insulin action, including in conditions when the response to insulin was lowered (during inflammation). LF was a promising, completely nontoxic, natural remedy which might be applied in long-term prophylaxis and therapy of metabolic disturbances, such as insulin resistance/type II diabetes [18].

It wasshown that circulating lactoferrin concentration was inversely associated with fasting triglyceride concentration $(\mathrm{r}=-0.24 ; \mathrm{P}=0.001)$, body mass index $(\mathrm{BMI})(\mathrm{r}=-0.20 ; \mathrm{P}=0.007)$, waist-to-hip ratio $(\mathrm{r}=-0.35 ; P$ $<0.001)$, and fasting glucose concentration $(\mathrm{r}=-0.18 ; \mathrm{P}=0.01)$, and directly correlated with HDL cholesterol concentration $(\mathrm{r}=0.21 ; \mathrm{P}=0.004)[11]$ and [12].

The increase of lactoferrinwas favorably associated with lipid levels and parametersof oxidative stress and inflammation.Lactoferrin had been described to inhibit selectiveuptake of HDL-cholesteryl esters by 35-50\% in humanprimary adipocytes and SW872 liposarcoma cells. Byinhibiting HDL uptake, lactoferrin could lead to preservation ofHDL-cholesterol levels after fat overload. This action seemed tobe mediated by the interaction of 
lactoferrin with low-densitylipoprotein-related protein. Low-density lipoprotein-relatedprotein contributes physiologically to HDL-cholesteryl esterselective uptake in adipocytes. Lactoferrin would also inhibit the interaction of lipoprotein lipase with low-density lipoprotein-related protein[15].

So our results can conclude that elevation of serum LF concentration may play an important role in returning the immunity balance to the prime state by its action in recurrence of immunity of diabetic patients especially the vascular dysfunction which represents the main problem of Egyptian diabetic patients that result from elevation of serum arginase. Detection of both arginase activity and lactoferrin concentration may act as new parameters to evaluate the sequel of the diabetes especially concerning the major and minor vasculopathy in Egyptian diabetic patients.Also, in the future research in the pharmacology field, we can use these results for arginase activity and LF concentration as a target for controlling the diabetes complications.

\section{Acknowledgments:-}

This work was financially supported by Faculty of Science, Cairo University and NationalDiabetes and Endocrinology Institute.

\section{Reference:-}

1. You H., Bo P., Sunmin P., Sung-HoonK.(2011): A Comparative Study of Eating Habits and Food Intake in Women with Gestational Diabetes according to Early Postpartum Glucose Tolerance Status. Diabetes Metab. J., 35:354-363.

2. Britney G., Mary S., James T., Lily W., Phil D., Joy J., Pamela F., Priyaanka N., George E., and Thomas A. (2010): Genome-Wide Analysis of Copy Number Variation in Type 1 Diabetes. Plos One, 5(11): 1-8.

3. Wu G and Morris SM. (1998): Arginine metabolism:nitric oxide and beyond. The Biochemical Journal 336 (Pt1): $1-17$.

4. Sharma S, Sinha M, Kaushik S, Kaur P, Singh TP. (2013):C-lobe of lactoferrin: the whole story of the halfmolecule.Biochem. Res. Int., 2013:271641.

5. Fruzsina J., Robert J., Kelly P., Ahmad S. and William D. (2013): Arginase promotes skeletal muscle arteriolar endothelial dysfunction in diabetic rats. Immunology, 4(119): 1-7.

6. Jelodar G, Razmi N, Gholampour V. (2007): Arginase alteration in the reproductive system of alloxan-diabetic dogs.J. Reprod. Dev., 53(2):317-321.

7. Jochen S., Daniel N., and Dan B. (2013): Development of novel arginase inhibitors for therapy of endothelial dysfunction. Immunology, 4(278): 1-6.

8. Serafi'n R.-Z., Miguel M.-R., Marisela O., Lourdes S.-S., Miguel Q.-Q., Norberto G.-G., Rolando H.-M. (2013): Increased Erythrocytes By-Products of Arginine Catabolism Are Associated with Hyperglycemia and Could Be Involved in the Pathogenesis of Type 2 Diabetes Mellitus. PLOS ONE, 8 (6):e66823.

9. Salimuddin, Kailash U., and Najma B. (1999): Effects of Vanadate on Expression of Liver Arginase in Experimental Diabetic Rats. IUBMB Life, 48: 237-240.

10. Jun-Ichi T., Hajime N., Katsuaki T., Masahiko I., Tadashi U., Atsushi N., Makoto N., Shinobu S., Toshifumi S., and Hisahiko S. (2002): Lactoferrin reduces colitis in rats via modulation of the immune system and correction of cytokine imbalance. Am. J. Physiol. Gastrointest. Liver Physiol., 283: G187-G195.

11. Moreno-Navarrete J. M., Ortega F.J., Bassols J., Ricart W., and Ferna'ndez-Real J. M. (2009): Decreased Circulating Lactoferrin in Insulin Resistance and Altered Glucose Tolerance as a Possible Marker of Neutrophil Dysfunction in Type 2 Diabetes. J. Clin. Endocrinol.Metab., 94: 4036-4044.

12. Jose' M.-N., Francisco O., Judit B., Antoni C., Wifredo R., and Jose' F.-R. (2008): Association of Circulating Lactoferrin Concentration and 2 NonsynonymousLTF Gene Polymorphisms with Dyslipidemia in Men Depends on Glucose-Tolerance Status. Clinical Chemistry, 54(2):301-309.

13. Beata N., Marcin F., Tomasz K., Maja K., Micha Z. (2010): Lactoferrin inhibits the growth of nasal polypfibroblasts. Pharmacoligical Reports, 62: 1139-1147.

14. Ben-Aryeh H., Serouya R. Kanter Y., Szargel R., and Laufer D. (1993): Oral health and salivary composition in diabetic patients. J. Diabetes Complications, 7(1):57-62.

15. José F., Eduardo G.-F., José M.-N., Mora M.-P., Lourdes G.-S., Wifredo R., and Francisco T. (2010): Fat Overload Induces Changes in Circulating Lactoferrin That Are Associated with Postprandial Lipemia and Oxidative Stress in Severely Obese Subjects. Obesity, 18: 482-488.

16. Dodds M.W., Yeh C.K., and Johnson D.A. (2000): Salivary alterations in type 2 (non-insulin dependent) diabetes mellitus and hypertension. Community Dent. Oral Epidemiol., 28(5): 373-381.

17. Vengen I.T., Dale A.C., Wiseth R., Midthjell K., and Videm V. (2010): Lactoferrin is a novel predicator of fatal ischemic heart disease in diabetes mellitus type 2: long-term follow-up of the HUNT1 study. Atherosclerosis, 212(2): 614-620.

18. Artym J. (2012):A remedy against obesity? The role of lactoferrin in the metabolism of glucose and lipids.Postepy.Hig. Med. Dosw. (Online)., 66:937-953. 